HER STORIES 
CONSOLE-ING PASSiOns: Television and Cultural Power Edited by Lynn Spigel 


\section{HER STORIES}

DAYTIME SOAP OPERA \& US TELEVISION HISTORY

Elana Levine

Duke University Press Durham and London 2020 
(C) 2020 DUKE UNIVERSITY PRESS. All rights reserved.

Printed in the United States of America on acid-free paper $\infty$ Designed by Courtney Leigh Baker Typeset in Minion Pro and Trade Gothic by Westchester Publishing Services.

Library of Congress Cataloging-in-Publication Data Names: Levine, Elana, [date] author.

Title: Her stories : daytime soap opera and US television history / Elana Levine.

Description: Durham : Duke University Press, 2020. | Series: Console-ing passions | Includes bibliographical references and index.

Identifiers: LCCN 2019023970 (print)

LCCN 2019023971 (ebook)

ISBN 9781478007661 (hardcover)

ISBN 9781478008019 (paperback)

ISBN 9781478009061 (ebook)

Subjects: LCsH: Television soap operas-United States-History and criticism.

Classification: LCC PN1992.8.S4 L47 2020 (print) | LCC PN1992.8.S4 (ebook) | DDC 791.45/69287-dc23

LC record available at https://lccn.loc.gov/2019023970

LC ebook record available at https://lccn.loc.gov/2019023971

Cover art: Tv playwright Agnes E. Nixon. ( C Charles Bonnay/ The LIFE Images Collection. Courtesy Getty Images. 